\title{
Induction therapy for locally advanced distal esophageal adenocarcinoma: Is radiation Always necessary?
}

Douglas Z. Liou, MD, ${ }^{\mathrm{a}}$ Leah M. Backhus, MD, ${ }^{\mathrm{a}, \mathrm{b}}$ Natalie S. Lui, MD, ${ }^{\mathrm{a}}$ Joseph B. Shrager, MD, ${ }^{\mathrm{a}}$ and Mark F. Berry, MD ${ }^{\mathrm{a}, \mathrm{b}}$

\section{ABSTRACT}

Objective: To compare outcomes between induction chemotherapy alone (ICA) and induction chemoradiation (ICR) in patients with locally advanced distal esophageal adenocarcinoma.

Methods: Patients in the National Cancer Database treated with ICA or ICR followed by esophagectomy between 2006 and 2012 for cT1-3N1M0 or T3N0M0 adenocarcinoma of the distal esophagus were compared using logistic regression, Kaplan-Meier analysis, and Cox proportional hazards methods.

Results: The study group included 4763 patients, of whom 4323 patients $(90.8 \%)$ received ICR and 440 patients $(9.2 \%)$ received ICA. There were no differences in age, sex, race, Charlson Comorbidity Index, treatment facility type, clinical T or $\mathrm{N}$ status between the 2 groups. Tumor size $\geq 5 \mathrm{~cm}$ (odds ratio, $1.46 ; P=.006$ ) was the only factor that predicted ICR use. Higher rates of T downstaging $(39.7 \% \mathrm{vs}$ $33.4 \% ; P=.012)$, N downstaging $(32.0 \%$ vs $23.4 \% ; P<.001)$, and complete pathologic response $(13.1 \%$ vs $5.9 \% ; P<.001)$ occurred in ICR patients. Positive margins were seen more often in ICA patients $(9.6 \%$ vs $5.5 \% ; P=.001)$, but there was no difference in 5-year survival (ICR $35.9 \%$ vs ICA $37.2 \%$; $P=.33$ ), and ICR was not associated with survival in multivariable analysis (hazard ratio $=1.04 ; P=.61)$.

Conclusions: ICR for locally advanced distal esophageal adenocarcinoma is associated with a better local treatment effect, but not improved survival compared with ICA, which suggests that radiation can be used selectively in this clinical situation. (J Thorac Cardiovasc Surg 2018;155:2697-707)

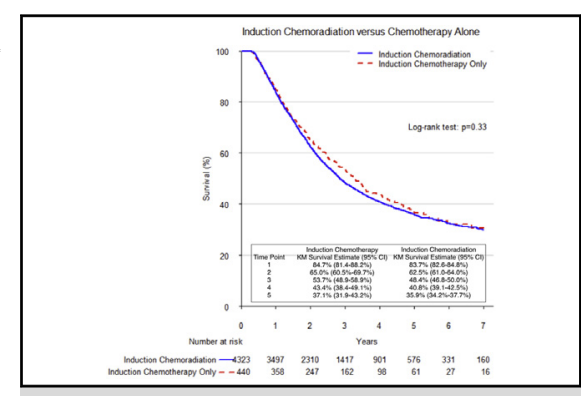

Survival curve showing no difference in long-term survival between ICA and ICR patients.

\section{Central Message}

Radiation during induction therapy may not be uniformly necessary for all patients with locally advanced distal esophageal adenocarcinoma undergoing esophagectomy.

\section{Perspective}

Studies on induction therapy for esophageal cancer comprise heterogeneous patient populations; thus, the optimal induction strategy for specific patient subsets are not clear. We compared ICA to ICR in patients with locally advanced distal esophageal adenocarcinoma and found no difference in long-term survival. Our results suggest that radiation can be used selectively during induction therapy.

See Editorial Commentary page 2708.
The incidence of esophageal cancer continues to increase, although at a slower in more recent years. An estimated 16,940 new cases will be diagnosed in the United States in 2017. ${ }^{1}$ Epidemiologic shifts over the past several decades have resulted in adenocarcinoma of the distal esophagus or

\footnotetext{
From the a Department of Cardiothoracic Surgery, Stanford University Medical Center, Stanford, Calif; and ${ }^{b}$ VA Palo Alto Health Care System, Palo Alto, Calif. Read at the 97th Annual Meeting of The American Association for Thoracic Surgery, Boston, Massachusetts, April 29-May 3, 2017.

Received for publication April 30, 2017; revisions received Nov 14, 2017; accepted for publication Dec 28, 2017; available ahead of print March 9, 2018.

Address for reprints: Mark F. Berry, MD, Falk Cardiovascular Research Institute,

Stanford, CA (E-mail: berry037@stanford.edu).

$0022-5223 / \$ 36.00$

Copyright (c) 2018 by The American Association for Thoracic Surgery

https://doi.org/10.1016/j.jtcvs.2017.12.136
}

esophagogastric junction (EGJ) being the most common clinical entity of esophageal cancer in the Western world, ${ }^{2,3}$ although globally squamous cell cancer remains more common. Patients with esophageal adenocarcinoma and squamous cell carcinoma have previously been observed to achieve similar long-term survival across major treatment modalities, ${ }^{3,4}$ and treatment guidelines have

- Scanning this QR code will take you to a supplemental video. To view the AATS Annual Meeting Webcast, see the URL next to the webcast thumbnail. 


\section{Abbreviations and Acronyms \\ AJCC = American Joint Committee on Cancer \\ $\mathrm{CoC}=$ Commission on Cancer \\ CROSS $=$ Chemoradiotherapy for Oesophageal \\ Cancer Followed by Surgery Study \\ EGJ = esophagogastric junction \\ $\mathrm{HR}=$ hazard ratio \\ ICA = induction chemotherapy alone \\ ICR = induction chemoradiation \\ IQR = interquartile range \\ MAGIC $=$ Medical Research Council Adjuvant \\ Gastric Infusional Chemotherapy \\ $\mathrm{NCCN}=$ National Comprehensive Cancer Network \\ $\mathrm{NCDB}=$ National Cancer Database}

historically been essentially equivalent for both histologies. However, there is accumulating evidence that tumor histology has a significant influence on survival after treatment. ${ }^{5-7}$ As such, the seventh edition of the American Joint Committee on Cancer (AJCC) TMN Staging System and the most recent National Comprehensive Cancer Network (NCCN) Clinical Practice Guidelines include separate stage groups and treatment algorithms for the 2 histologic subtypes. ${ }^{8,9}$

Locally advanced esophageal cancer is increasingly treated with induction therapy before esophagectomy based on relatively recent large randomized trials that have shown benefit to this approach. ${ }^{10,11}$ However, the optimal induction therapy strategy for patients with locally advanced esophageal adenocarcinoma is not clear. The Medical Research Council Adjuvant Gastric Infusional Chemotherapy (MAGIC) and Chemoradiotherapy for Oesophageal Cancer Followed by Surgery Study (CROSS) trials are 2 randomized trials that showed benefit of induction therapy for patients with adenocarcinoma of the distal esophagus or EGJ, but different induction strategies were used. The MAGIC trial investigated the use of perioperative chemotherapy, but it primarily included patients with gastric adenocarcinoma, although approximately $25 \%$ of patients had adenocarcinoma of the distal esophagus or EGJ. ${ }^{11}$ The CROSS trial investigated the use of induction chemoradiation, but included patients with both squamous cell carcinoma and adenocarcinoma of the esophagus or EGJ. ${ }^{10}$ Other studies have also shown improved survival with both chemotherapy and chemoradiation before surgery for locally advanced adenocarcinoma ${ }^{12-15}$; therefore, either strategy is considered acceptable according to NCCN guidelines. ${ }^{9}$ Because direct comparisons of induction chemotherapy and induction chemoradiation are limited, ${ }^{16,17}$ the aim of this study was to test the hypothesis that long-term survival was better after chemoradiation compared with chemotherapy alone for locally advanced distal esophageal adenocarcinoma using a large, nationwide cancer database.

\section{METHODS \\ Data Source}

This retrospective National Cancer Database (NCDB) analysis was approved by the Stanford University Institutional Review Board. The NCDB is a joint venture between the American College of Surgeons Commission on Cancer $(\mathrm{CoC})$ and the American Cancer Society, and it is estimated to capture $70 \%$ of all newly diagnosed cancers in the United States. The database collects data from more than $1500 \mathrm{CoC}$-approved facilities in North America, and it currently contains more than 30 million records. AJCC staging data are directly available, concomitant with year of diagnosis. During the study period, the AJCC editions 5, 6, and 7 were used to identify patients for inclusion. Although the AJCC seventh edition further distinguished $\mathrm{T} 1$ tumors into $\mathrm{T} 1 \mathrm{a}$ and $\mathrm{T} 1 \mathrm{~b}$, no changes across editions in the overall definition of $\mathrm{T} 1$ or N0 disease were made; therefore, there were no attempts to recode the clinical staging data manually. The use of esophagectomy was determined using Facility Oncology Registry Data Standards codes.

\section{Patient Selection}

Patients with AJCC cT1-3N1M0 or cT3N0 adenocarcinoma of the distal or abdominal esophagus diagnosed during 2006-2012 and treated with esophagectomy after induction chemotherapy with or without radiation were included for analysis (Figure 1). The choice of this study period was based on the availability of data in the NCDB at the time of analysis. Only patients without missing histology; tumor location; TNM stage; known use and sequence of surgery, chemotherapy, and radiation; or survival data were included in the overall analysis. Patients with missing data for any of the variables included in the logistic regression and proportional hazards models were not included in these models. Patients with previous malignancies and incompletely recorded follow-up data were excluded.

\section{Statistical Analysis}

Patients were stratified into 2 groups based on whether induction chemotherapy alone (ICA) or induction chemoradiation (ICR) was used before esophagectomy. Baseline characteristics between groups were

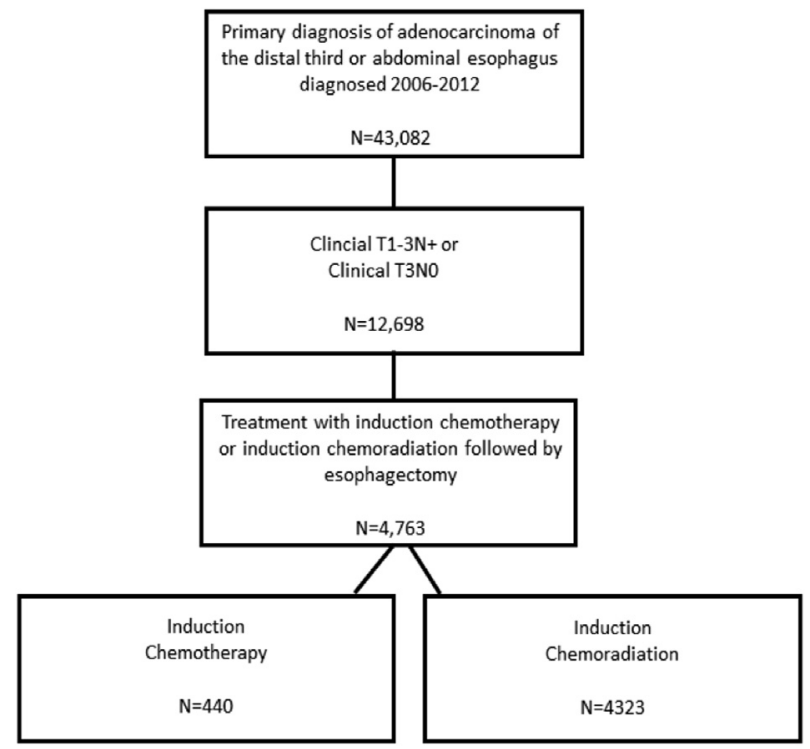

FIGURE 1. CONSORT diagram. CONSORT diagram showing schema of study subject selection. 
compared with the Wilcoxon rank-sum test for continuous variables and Pearson's chi-square test for discrete variables. The Fisher exact test was used for those discrete variables with fewer than 5 outcomes. Independent predictors of the use of induction radiation in addition to induction chemotherapy before esophagectomy were estimated with a multivariable logistic regression model, including age, sex, race, insurance status, Charlson Comorbidity Index, median census tract income level, treatment facility type, distance traveled to facility, tumor size, clinical $\mathrm{T}$ stage, and clinical $\mathrm{N}$ stage. Survival between groups was assessed with the Kaplan-Meier method, log-rank test, and Cox proportional hazards model. Variables chosen for inclusion in the Cox model were patient (age, sex, comorbidities) and stage characteristics ( $\mathrm{T}$ stage, nodal involvement, tumor size) previously shown to be associated with survival, along with the study variable of interest (ICR vs ICA). This Cox model was adjusted for clustering by hospital by including the specific facility in the model as a random effect A $P$ value $<.05$ was considered statistically significant. All analyses were

TABLE 1. Baseline demographics and characteristics

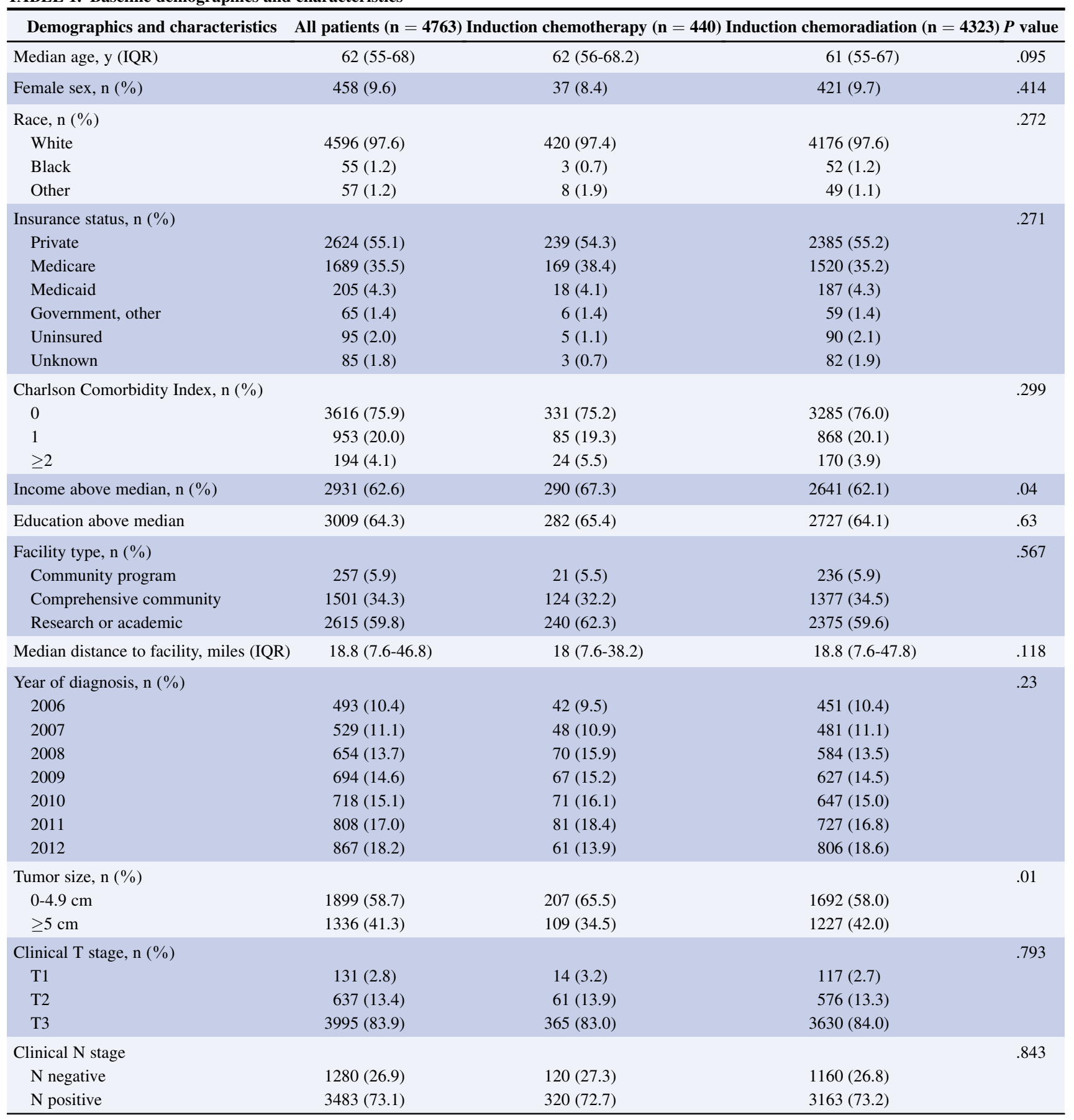

$I Q R$, Interquartile range. 
performed using R version 3.2.2 (R Foundation for Statistical Computing, Vienna, Austria).

\section{RESULTS}

During the study period, a total of 43,082 patients had a primary diagnosis of adenocarcinoma of the distal third or abdominal esophagus, with 12,698 patients presenting as clinical stage T1-3N1M0 or T3N0. Of these, 4763 patients underwent induction therapy followed by esophagectomy, with $440(9.2 \%)$ receiving ICA and $4323(90.8 \%)$ receiving ICR (Figure 1). Baseline characteristics of the study population are presented in Table 1 . The mean age of the entire cohort was 62 years, and $9.6 \%$ were female. There were no differences in age, sex, race, insurance status, or Charlson comorbidity index between the two groups. ICA had a greater number of patients with income level above the median census tract compared with ICR $(67.3 \%$ vs $62.1 \% ; P=.04)$, although the education levels were comparable. The hospital facility type and distance traveled to facility were similar. There was no difference in the use of ICA versus ICR based on year of diagnosis. Radiation dose was specifically recorded in $3751(87 \%)$ of ICR patients, with a median radiation dose of 45 Gy (interquartile range [IQR], 45-50.4 Gy). Patients who received ICR had a higher percentage of tumors $\geq 5 \mathrm{~cm}$ in size compared with ICA $(42.0 \%$ vs $34.5 \% ; P=.01)$; however, there were no differences in clinical $\mathrm{T}$ or $\mathrm{N}$ stage.
Overall, the 4763 patients in the study were treated at 790 facilities. The number of patients treated at each facility ranged from 1 to 189 (median, 3 [IQR 1-6]). Most facilities $(\mathrm{n}=609 ; 77 \%)$ treated at least $90 \%$ of their patients with chemoradiation, such that $80 \%(n=3440)$ of the entire ICR cohort but only $17 \%(n=74)$ of the entire ICA cohort were treated at these chemoradiation-favoring facilities. In contrast, only $32(4 \%)$ of the facilities treated at least $90 \%$ of their patients with chemotherapy alone, such that only $2(0.05 \%)$ ICR patients and $58(13 \%)$ ICA patients were treated at these chemotherapy-favoring facilities. Only $89(11 \%)$ facilities had a relatively balanced mix of induction strategy use that ranged from $25 \%$ to $75 \%$ for either treatment. Treatment at these facilities included 267 $(6 \%)$ ICR patients and 170 (39\%) ICA patients.

Predictors of receiving radiation in addition to induction chemotherapy based on multivariable logistic regression included tumor size $\geq 5 \mathrm{~cm}$ (odds radio, $1.46 ; P=.006$; Table 2). Age, sex, race, insurance status, Charlson comorbidity index, income level, facility type, distance traveled to facility, and clinical $\mathrm{T}$ or $\mathrm{N}$ stage were not independent predictors of including radiation as a part of the induction therapy regimen.

Peritreatment outcomes were compared between ICA and ICR patients (Table 3). There was no difference in the number of days between induction therapy and definitive surgery. The surgical specimen from ICR patients had fewer

TABLE 2. Multivariable predictors of radiation

\begin{tabular}{|c|c|c|c|c|}
\hline Variable & Odds ratio & 95\% CI lower & 95\% CI higher & $P$ value \\
\hline Age (per decade) & 1.000 & 0.843 & 1.187 & .998 \\
\hline Female sex & 1.071 & 0.699 & 1.641 & .752 \\
\hline \multicolumn{5}{|l|}{ Race (vs white) } \\
\hline Black & 2.693 & 0.362 & 20.051 & .333 \\
\hline Other & 0.607 & 0.232 & 1.587 & .308 \\
\hline \multicolumn{5}{|l|}{ Insurance status (vs private) } \\
\hline Medicare or Medicaid & 0.930 & 0.683 & 1.267 & .646 \\
\hline Government, other & 0.842 & 0.292 & 2.429 & .751 \\
\hline Uninsured & 2.020 & 0.623 & 6.551 & .241 \\
\hline Unknown & 1.991 & 0.470 & 8.438 & .350 \\
\hline \multicolumn{5}{|l|}{ Charlson comorbidity index (vs 0 ) } \\
\hline 1 & 0.962 & 0.696 & 1.330 & .816 \\
\hline$\geq 2$ & 0.710 & 0.404 & 1.247 & .233 \\
\hline Income above median & 0.913 & 0.697 & 1.195 & .507 \\
\hline Facility type (research or academic vs community) & 0.823 & 0.630 & 1.076 & .154 \\
\hline Distance traveled (per 50 miles) & 1.077 & 0.991 & 1.171 & .082 \\
\hline Tumor size ( $\geq 5 \mathrm{vs}<5 \mathrm{~cm}$ ) & 1.463 & 1.116 & 1.917 & .006 \\
\hline \multicolumn{5}{|l|}{ Clinical T stage (vs T1) } \\
\hline $\mathrm{T} 2$ & 1.549 & 0.727 & 3.302 & .257 \\
\hline $\mathrm{T} 3$ & 1.393 & 0.697 & 2.785 & .349 \\
\hline Clinical $\mathrm{N}$ positive & 1.037 & 0.772 & 1.393 & .808 \\
\hline
\end{tabular}

CI, Confidence interval. 
TABLE 3. Comparison of perioperative variables

\begin{tabular}{|c|c|c|c|}
\hline Variable & Induction chemotherapy $(n=440)$ & Induction chemoradiation $(n=4323)$ & $P$ value \\
\hline Days to definitive surgery, median (IQR) & $132(114-152.2)$ & $130(112-153)$ & .43 \\
\hline $\mathrm{T}$ downstaging & $147(33.4 \%)$ & $1715(39.7 \%)$ & .012 \\
\hline $\mathrm{N}$ downstaging & $103(23.4 \%)$ & $1383(32.0 \%)$ & $<.001$ \\
\hline Complete pathologic response & $26(5.9 \%)$ & $566(13.1 \%)$ & $<.001$ \\
\hline Nodes examined, median (IQR) & $16(10-22)$ & $11(6-18)$ & $<.001$ \\
\hline Positive surgical margins & $41(9.6 \%)$ & $226(5.5 \%)$ & .001 \\
\hline $\begin{array}{l}\text { Surgical margins } \\
\text { R0 } \\
\text { R1 } \\
\text { R2 } \\
\text { Positive, not otherwise specified }\end{array}$ & $\begin{array}{c}387(90.4 \%) \\
20(4.7 \%) \\
1(0.2 \%) \\
20(4.7 \%)\end{array}$ & $\begin{array}{c}3893(94.5 \%) \\
135(3.3 \%) \\
1(0 \%) \\
90(2.2 \%)\end{array}$ & .001 \\
\hline Adjuvant chemotherapy & $110(25.0 \%)$ & $360(8.3 \%)$ & $<.001$ \\
\hline Adjuvant radiation & $104(23.6 \%)$ & $32(0.7 \%)$ & $<.001$ \\
\hline Hospital length of stay, d (IQR) & $9(8-13.5)$ & $10(7-14)$ & .864 \\
\hline Unplanned 30-d same-hospital readmission & $18(4.1 \%)$ & $236(5.5 \%)$ & .146 \\
\hline 30-d mortality & $11(2.5 \%)$ & $113(2.6 \%)$ & .999 \\
\hline 90-d mortality & $30(7 \%)$ & $293(6.9 \%)$ & .999 \\
\hline
\end{tabular}

$I Q R$, Interquartile range.

median number of lymph nodes examined (11 vs 16; $P<.001)$. Patients receiving ICR had a higher incidence of T downstaging $(39.7 \%$ vs $33.4 \% ; P=.01)$ and $\mathrm{N}$ downstaging $(32.0 \%$ vs $23.4 \% ; P<.001)$. Complete pathologic response was also higher in the ICR group $(13.1 \%$ vs $5.9 \%$; $P<.001$ ), and ICR patients had a lower incidence of positive margins $(5.5 \%$ vs $9.6 \% ; P=.001)$. ICA patients underwent adjuvant chemotherapy $(25.0 \%$ vs $8.3 \%$; $P<.001)$ and adjuvant radiation $(23.6 \%$ vs $0.7 \%$; $P<.001)$ more frequently compared with ICR patients. There were no differences in hospital length of stay, 30day same-hospital readmissions, 30-day mortality, or 90day mortality between the 2 groups.

Based on Kaplan-Meier survival analysis, there was no difference in overall survival between ICA and ICR patients (Figure 2). The 5-year survival rate was $37.2 \%$ with ICA and $35.9 \%$ with ICR. Median survival was 39.1 months for ICA patients and 34.1 months for ICR patients $(P=.33)$. Cox proportional hazards model identified variables associated with survival (Table 4). Increasing age (hazard radio $[\mathrm{HR}]=1.17$ per decade; $P<.001$ ) and Charlson comorbidity index of 1 (HR $=1.18 ; P=.005)$ or 2 $(\mathrm{HR}=1.40 ; P=.003)$ were associated with worse survival, whereas female sex (HR $=0.83 ; P=.02)$ was protective. Although clinical stage T3 (HR $=1.48 ; P=.02)$ and positive $\mathrm{N}$ stage $(\mathrm{HR}=1.31 ; P<.001)$ were associated with worse survival, tumor size $\geq 5 \mathrm{~cm}$ was not $(\mathrm{HR}=1.04$; $P=.44)$. The use of induction chemoradiation was not significantly associated with survival $(\mathrm{HR}=1.04$; $P=.61$ ). Additional sensitivity analyses were performed using the Cox model for tumor size cutoff values of $3 \mathrm{~cm}$, $7 \mathrm{~cm}$, and tumor size as a continuous variable. All 3 analyses showed findings consistent with the primary analysis, in particular that the use of induction chemoradiation was not associated with improved survival.

\section{DISCUSSION}

Induction therapy for esophageal cancer has been studied extensively, and much of the evidence supports its use in locally advanced disease. Although some trials failed to identify survival benefit, which is likely related to methodological differences, this practice has been adopted widely because of multiple randomized studies demonstrating improved survival compared with surgery alone. ${ }^{10-15}$ However, generalizing these findings across all subsets of esophageal cancer patients is difficult because of the heterogeneity among studies with respect to histology and method of induction therapy. Squamous cell carcinomas and adenocarcinomas of the esophagus are increasingly recognized as separate disease entities with distinct clinicopathologic profiles. ${ }^{18}$ Accordingly, the 2 histologic subtypes have differing pathologic responses, recurrence rates, and prognostic outlook following induction therapy. ${ }^{6,10,19,20}$ This highlights the importance of studying each disease entity independently to best characterize the optimal treatment strategies.

In the current study, we specifically examined the influence of induction therapy on survival in patients with locally advanced distal esophageal adenocarcinoma. Patients treated with ICR had higher rates of tumor 


\section{Induction Chemoradiation versus Chemotherapy Alone}

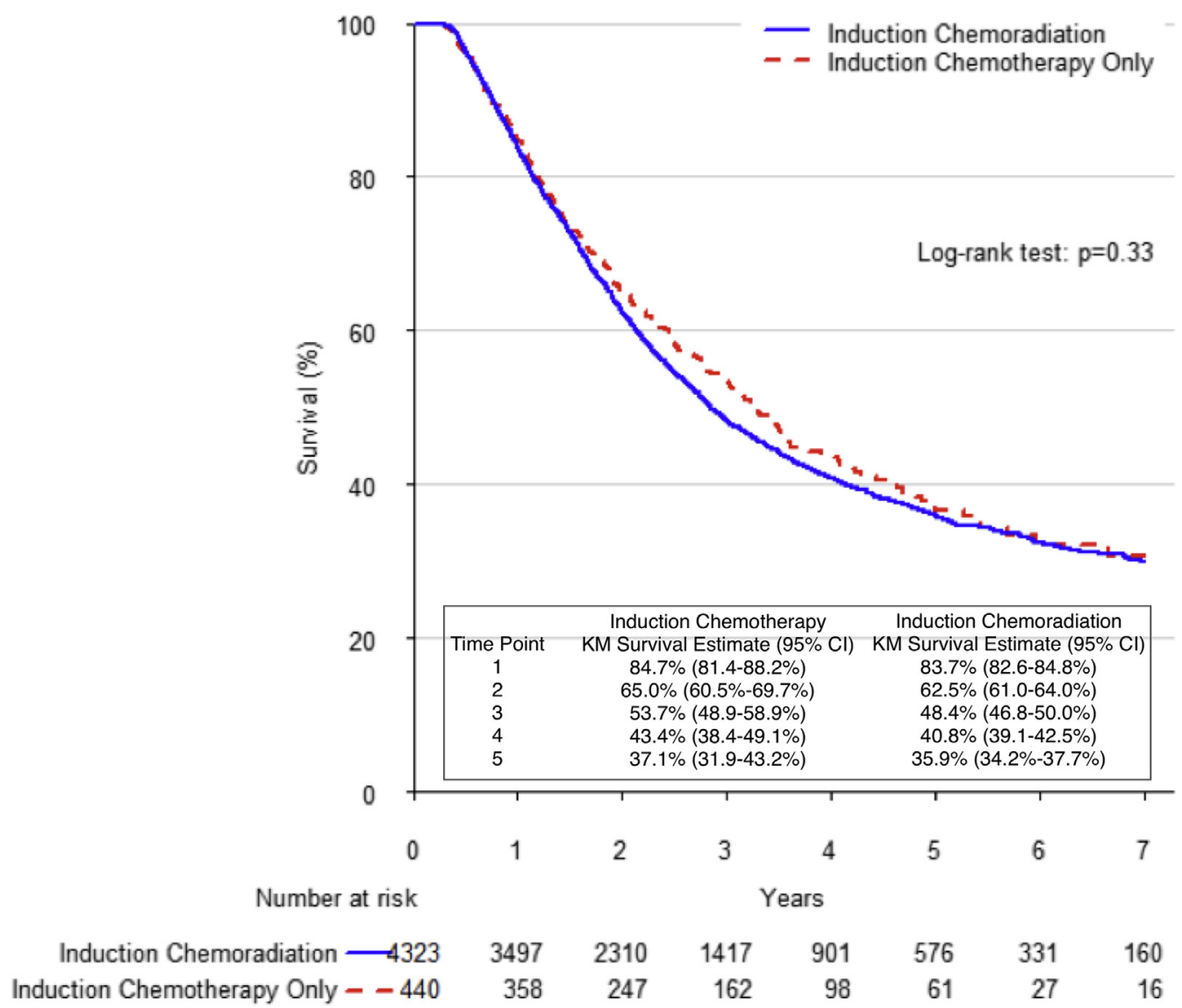

FIGURE 2. Kaplan-Meier survival analysis. Kaplan-Meier survival curve showing no difference in long-term survival between patients treated with induction chemotherapy alone versus induction chemoradiation. $K M$, Kaplan-Meier; $C I$, confidence interval.

downstaging, but this improved local response did not translate to a survival benefit in our analysis (Video 1). Previous studies in the literature have compared ICA with ICR for

TABLE 4. Cox proportional hazards model

\begin{tabular}{lcc}
\hline \multicolumn{1}{c}{ Variable } & $\begin{array}{c}\text { Hazard ratio (95\% } \\
\text { Confidence interval) }\end{array}$ & $\boldsymbol{P}$ value \\
\hline Age (per decade) & $1.17(1.11-1.23)$ & $<.001$ \\
Female sex & $0.83(0.70-0.98)$ & .02 \\
Charlson Comorbidity Index & & \\
$\quad($ reference $=0)$ & $1.18(1.05-1.33)$ & .005 \\
1 & $1.40(1.12-1.74)$ & .003 \\
$\geq 2$ & $1.04(0.94-1.14)$ & .44 \\
Tumor size $\geq 5$ cm & & \\
T stage (reference $=$ T1) & $1.15(0.80-1.64)$ & .44 \\
T2 & $1.48(1.06-2.07)$ & .02 \\
$\quad$ T3 & $1.31(1.17-1.46)$ & $<.001$ \\
Clinical N positive & $1.04(0.89-1.22)$ & .61 \\
\hline Induction chemoradiation & & \\
\hline
\end{tabular}

esophageal cancer, ${ }^{16,17,21-25}$ but few investigated adenocarcinoma exclusively. ${ }^{16,17,22,24}$ Three randomized trials conducted in Europe and Australia compared ICA with ICR, two of which included only patients with adenocarcinoma $^{16,17}$ and the third included both histologic subtypes. ${ }^{21}$ The conclusions were essentially the same as the current study-namely, an improved local tumor effect with the addition of radiation but no significant survival benefit. All 3 studies, however, were underpowered to detect a difference in survival because of low accrual. In addition, there are several retrospective analyses in the literature, ${ }^{22-26}$ most of which include both squamous cell carcinoma and adenocarcinoma, and all but one found no survival benefit with ICR compared with ICA. The exception was a single-institution series by MD Anderson comprising 157 patients accrued through 4 separate sequential phase II/III randomized trials during 1990-2005. ${ }^{25}$ Swisher and colleagues ${ }^{25}$ demonstrated improved complete pathologic response and overall survival with ICR, although considerable limitations to this study were the different staging modalities and induction regimens within the 


\section{Stanford MEDICINE}

\section{Induction Therapy for Locally Advanced Distal Esophageal Adenocarcinoma: Is Radiation Always Necessary?}

DZ Liou, LM Backhus, N Lui, JB Shrager, MF Berry

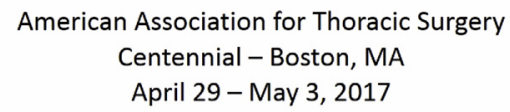

VIDEO 1. Video summarizing the importance and relevance of the findings from this study. Video available at: http://www.jtcvsonline.org/ article/S0022-5223(18)30309-X/fulltext.

same treatment groups, and the relatively lengthy study period spanning 15 years. Samson and colleagues ${ }^{23}$ also conducted a retrospective analysis comparing ICA and ICR using the NCDB. The authors showed better locoregional control but no improvement in survival with the addition of radiation, which is consistent with findings from the current study, although the study population was slightly different. Samson and colleagues ${ }^{23}$ included patients with adenocarcinoma, squamous cell carcinoma, and earlystage tumors (cT0-2N0). In contrast, the focus of the current study was to investigate specifically those patients with locally advanced adenocarcinoma.

It is unclear why a better local treatment effect with ICR compared to ICA was not associated with improved survival in our series, as tumor downstaging after induction therapy has significant prognostic value. ${ }^{20,27}$ One consideration may be that most patients who relapse after esophageal adenocarcinoma have distant disease rather than local recurrence. Therefore, having a slightly higher but relatively small number of patients with positive margins in the ICA group might not be enough to result in an overall survival difference compared with ICR.

There are several notable findings from our analysis that may also potentially contribute to this discrepancy. One factor may be related to the lymphadenectomy. ICR patients had significantly fewer lymph nodes examined compared with ICA patients (median 11 vs $16 ; P<.001$ ). Adequate lymphadenectomy during esophagectomy has been shown to improve survival in patients undergoing surgery alone. ${ }^{28}$ However, data regarding the value of extended lymph node dissection following ICR are mixed. ${ }^{29-31} \mathrm{~A}$ post hoc analysis of the CROSS study found that the number of lymph nodes resected was associated with survival in patients who underwent surgery alone, but not in patients who received ICR followed by surgery. ${ }^{29}$ The authors attribute this finding to a net treatment effect on positive nodes from the induction therapy rather than the type of esophagectomy performed or poor quality surgery. Despite this, NCCN guidelines recommend a similar number of lymph nodes, at least 15 , regardless of induction therapy status for adequate nodal staging. ${ }^{9}$ ICR patients in our series had a median of 11 lymph nodes examined, which some might consider suboptimal for nodal clearance and staging.

Another relevant finding is the difference in adjuvant therapy use after esophagectomy between ICA and ICR patients (chemotherapy $25.0 \%$ vs $8.3 \%, P<.001$; radiation $23.6 \%$ vs $0.7 \%, P<.001)$. This is most likely due to a lower incidence of nodal disease and positive margins in patients treated with ICR, although other factors may contribute, such as a patient's ability to tolerate further therapy after a course of chemoradiation followed by major surgery. Regardless, this difference could partially explain why a better local treatment effect with ICR does not lead to improved survival over ICA. It is conceivable that the local treatment effect rendered from ICR can be balanced by a higher incidence of adjuvant therapy in ICA patients, thus eliminating any statistical survival benefit between the 2 groups. Furthermore, the decision to pursue adjuvant therapy in ICR patients may in part be diminished by inadequate nodal staging, as theorized earlier. It should be noted that some surgeons favor preoperative over postoperative radiation to avoid radiating the conduit used to replace the esophagus. However, these results suggest that many patients can be treated with chemotherapy alone, and adjuvant radiation to the area of the conduit can be used selectively in situations of positive margins.

Lastly, patients in our series who received ICR had significantly larger tumors than did patients who received ICA, and tumor size of $5 \mathrm{~cm}$ or greater predicted the use of radiation in addition to induction chemotherapy. It is difficult to explain these findings based on our data, but intuitively patients with bulky tumors may be more likely to receive radiation based on providers' biases on the need and potential benefit for achieving a complete resection. The presence of dysphagia with larger tumors may also influence providers to treat with radiation in hopes of quickly palliating these symptoms. There is literature that suggests tumor size is associated not only with survival, but also regional lymph node metastasis. ${ }^{32,33}$ Although the clinical $\mathrm{N}$ status was not different between our 2 groups, high false-negative rates of locoregional lymph node staging with both positron emission tomographycomputed tomography and endoscopic ultrasonography has been described, ${ }^{32,34}$ particularly with larger tumors. ${ }^{35}$ The larger tumor size in our ICR group may be an indicator of advanced pathologic disease that was not detected by conventional clinical staging methods. If this were the case, however, the effects on survival may be modest, as tumor size was not statistically significant on our Cox regression analysis. 
Practice patterns for the use of induction therapy for esophageal adenocarcinoma across the United States heavily favored ICR at a ratio of approximately 10 to 1 . Patient characteristics, such as age and co-morbidities, and factors related to healthcare systems delivery, such as insurance status and type of treatment facility, were not significantly associated with the use of ICR over ICA. The only predictor of radiation use during induction therapy was tumor size of $5 \mathrm{~cm}$ or greater. The fact that no other variables were associated with ICR or ICA suggests that the choice of induction therapy is mostly due to provider or institutional preferences. Our results suggest that induction radiation can be used more selectively in patients with locally advanced distal esophageal adenocarcinoma. For example, radiation might not be necessary for patients in whom a complete resection with negative margins is believed likely based on the tumor at initial presentation. Conversely, radiation may improve the chance of complete resection in patients with large bulky tumors for whom complete resection may be less likely. Further study is needed to delineate which specific induction strategy is optimal on the basis of specific clinical situations.

There are several notable limitations to the current study. As with all retrospective studies, causality cannot be established between variables, but only an association. The extent of our analysis is confined to the data elements present in the NCDB. As such, data with respect to staging modalities and specific induction therapy regimens are lacking. Variability in staging modality can influence the pretreatment assessment of tumor size, and this could not be accounted for in our analysis. Details related to the surgical technique and surgeon specialty are also not available, which can potentially influence the extent of lymphadenectomy performed and quality of surgery. In addition, available data in the NCDB cannot be used to confirm that patients with EGJ tumors were appropriately classified and treated as esophageal rather than gastric adenocarcinoma. It is possible that patients who received induction chemotherapy alone were managed as gastric cancer according to the MAGIC trial protocol followed by gastrectomy, although the inclusion of these patients in the esophageal cancer dataset rather than gastric cancer dataset indicates that they were likely treated as esophageal cancer. Regarding staging, patients staged in the AJCC fifth and sixth editions as M1a because of celiac node involvement were excluded from our study cohort; however, these patients would have been staged as N-positive disease in the seventh edition and therefore included in the study cohort. Consequently, our findings may be applicable only to patients with periesophageal and perigastric nodal disease, but not celiac lymph node involvement. In general, the NCDB lacks granular data regarding short-term posttreatment outcomes. Complications are not listed in the $\mathrm{NCDB}$; therefore, the frequency and severity of adverse events can only be inferred on the basis of readmissions and perioperative mortality. Furthermore, the NCDB captures only same-hospital readmissions; therefore, the true incidence of postoperative readmissions is underestimated. The rate of complete pathologic response in our series is lower than the response rate reported in the CROSS trial. The reasons for this discrepancy are not entirely clear, but may be related to differences in patient population, treating institution, and specific induction regimens between study patients in the CROSS trial and patients from a nationwide database used in the current study. It is also notable that most patients included in this series were treated before the published results of the CROSS trial in 2012. Finally, an intent-to-treat analysis could not be performed because of the retrospective nature of the study.

In conclusion, patients with locally advanced adenocarcinoma of the esophagus have a better local treatment effect with induction chemoradiation compared with induction chemotherapy alone; however, this does not translate to improved survival after esophagectomy. Possible explanations may be related to differences in tumor size, the extent of lymphadenectomy, and the use of adjuvant treatment between the 2 induction strategies. These results suggest that routine use of radiation in addition to chemotherapy is not uniformly necessary for all patients undergoing esophagectomy. Further research is needed to determine patient and tumor characteristics for which radiation should be used selectively.

\section{Webcast}

You can watch a Webcast of this AATS meeting presentation by going to: https://aats.blob.core.windows.net/ media/17AM/2017-05-03/RM312/05-03-17_Room312_ 0730_Liou.mp4.

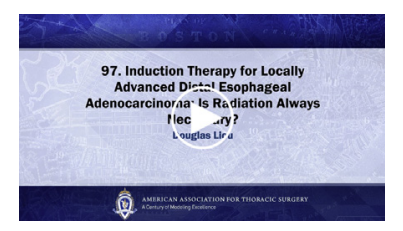

\section{Conflict of Interest Statement}

Authors have nothing to disclose with regard to commercial support.

The data used in this study are derived from a de-identified National Cancer Data Base file. The American College of Surgeons has executed a Business Associate Agreement that includes a data use agreement with each of its Commission on Cancer accredited hospitals. The American College of Surgeons and the Commission on Cancer have not verified and are not responsible for the analytic or statistical methodology employed, or the conclusions drawn from these data by the investigators. 


\section{References}

1. Siegel RL, Miller KD, Jemal A. Cancer statistics, 2017. CA Cancer J Clin. 2017; 67:7-30.

2. Brown LM, Devesa SS, Chow WH. Incidence of adenocarcinoma of the esophagus among white Americans by sex, stage, and age. J Natl Cancer Inst. 2008; 100:1184-7.

3. Dubecz A, Gall I, Solymosi N, Schweigert M, Peters JH, Feith M, et al. Temporal trends in long-term survival and cure rates in esophageal cancer: a SEER database analysis. J Thorac Oncol. 2012;7:443-7.

4. Chang DT, Chapman C, Shen J, Su Z, Koong AC. Treatment of esophageal cancer based on histology: a surveillance epidemiology and end results analysis. Am J Clin Oncol. 2009;32:405-10.

5. Siewert JR, Stein HJ, Feith M, Bruecher BL, Bartels H, Fink U. Histologic tumor type is an independent prognostic parameter in esophageal cancer: lessons from more than 1,000 consecutive resections at a single center in the Western world. Ann Surg. 2001;234:360-7; discussion 368-9.

6. Bollschweiler E, Metzger R, Drebber U, Baldus S, Vallböhmer D, Kocher M, et al. Histological type of esophageal cancer might affect response to neo-adjuvant radiochemotherapy and subsequent prognosis. Ann Oncol. 2009;20:231-8.

7. Rice TW, Rusch VW, Ishwaran H, Blackstone EH. Cancer of the esophagus and esophagogastric junction: data-driven staging for the seventh edition of the American Joint Committee on Cancer/International Union Against Cancer Cancer Staging Manuals. Cancer. 2010;116:3763-73.

8. Edge SB, Byrd DR, Compton CC, Fritz AG, Greene FL, Trotti A. AJCC Cancer Staging Manual. 7th ed. New York: Springer; 2010.

9. Ajani JA, D’Amico TA, Almhanna K, Bentrem DJ, Besh S, Chao J, et al. Esophageal and esophagogastric junction cancers, version 1.2015. J Natl Compr Canc Netw. 2015;13:194-227.

10. van Hagen P, Hulshof MC, van Lanschot JJ, Steyerberg EW, van Berge Henegouwen MI, Wijnhoven BP, et al. Preoperative chemoradiotherapy for esophageal or junctional cancer. N Engl J Med. 2012;366:2074-84.

11. Cunningham D, Allum WH, Stenning SP, Thompson JN, Van de Velde CJ, Nicolson M, et al. Perioperative chemotherapy versus surgery alone for resectable gastroesophageal cancer. N Engl J Med. 2006;355:11-20.

12. Ychou M, Boige V, Pignon JP, Conroy T, Bouché O, Lebreton G, et al. Perioperative chemotherapy compared with surgery alone for resectable gastroesophageal adenocarcinoma: an FNCLCC and FFCD multicenter phase III trial. J Clin Oncol. 2011;29:1715-21.

13. Tepper J, Krasna MJ, Niedzwiecki D, Hollis D, Reed CE, Goldberg R, et al. Phase III trial of trimodality therapy with cisplatin, fluorouracil, radiotherapy, and surgery compared with surgery alone for esophageal cancer: CALGB 9781. J Clin Oncol. 2008;26:1086-92.

14. Medical Research Council Oesophageal Cancer Working Group. Surgical resection with or without preoperative chemotherapy in oesophageal cancer: a randomised controlled trial. Lancet. 2002;35:1727-33.

15. Walsh TN, Noonan N, Hollywood D, Kelly A, Keeling N, Hennessy TP. A comparison of multimodal therapy and surgery for esophageal adenocarcinoma. $N$ Engl J Med. 1996;335:462-7.

16. Burmeister BH, Thomas JM, Burmeister EA, Walpole ET, Harvey JA, Thomson DB, et al. Is concurrent radiation therapy required in patients receiving preoperative chemotherapy for adenocarcinoma of the oesophagus? A randomised phase II trial. Eur J Cancer. 2011;47:354-60.

17. Stahl M, Walz MK, Stuschke M, Lehmann N, Meyer HJ, Riera-Knorrenschild J, et al. Phase III comparison of preoperative chemotherapy compared with chemoradiotherapy in patients with locally advanced adenocarcinoma of the esophagogastric junction. J Clin Oncol. 2009;27:851-6.

18. Siewert JR, Ott K. Are squamous and adenocarcinomas of the esophagus the same disease? Semin Radiat Oncol. 2007;17:38-44.

19. Luc G, Gronnier C, Lebreton G, Brigand C, Mabrut JY, Bail JP, et al. Predictive factors of recurrence in patients with pathological complete response after esophagectomy following neoadjuvant chemoradiotherapy for esophageal cancer: a multicenter study. Ann Surg Oncol. 2015;22(suppl 3):S1357-64.

20. Kelsen DP, Winter KA, Gunderson LL, Mortimer J, Estes NC, Haller DG, et al. Long-term results of RTOG trial 8911 (USA Intergroup 113): a random assignment trial comparison of chemotherapy followed by surgery compared with surgery alone for esophageal cancer. J Clin Oncol. 2007;25:3719-25.

21. Klevebro F, Alexandersson von Döbeln G, Wang N, Johnsen G, Jacobsen AB, Friesland S, et al. A randomized clinical trial of neoadjuvant chemotherapy versus neoadjuvant chemoradiotherapy for cancer of the oesophagus or gastrooesophageal junction. Ann Oncol. 2016;27:660-7.

22. Markar SR, Noordman BJ, Mackenzie H, Findlay JM, Boshier PR, Ni M, et al Multimodality treatment for esophageal adenocaricnoma: multi-center propensity-score matched study. Ann Oncol. 2017;28:519-27.

23. Samson P, Robinson C, Bradley J, Lockhart AC, Puri V, Broderick S, et al. Neoadjuvant chemotherapy versus chemoradiation prior to esophagectomy: impact on rate of complete pathologic response and survival in esophageal cancer patients. J Thorac Oncol. 2016;11:2227-37.

24. Spicer JD, Stiles BM, Sudarshan M, Correa AM, Ferri LE, Altorki NK, et al. Preoperative chemoradiation therapy versus chemotherapy in patients undergoing modified en bloc esophagectomy for locally advanced esophageal adenocarcinoma: is radiotherapy beneficial? Ann Thorac Surg. 2016;101:1262-9; discussion 1969-70.

25. Swisher SG, Hofstetter W, Komaki R, Correa AM, Erasmus J, Lee JH, et al Improved long-term outcome with chemoradiotherapy strategies in esophageal cancer. Ann Thorac Surg. 2010;90:892-8; discussion 898-9.

26. Luu TD, Gaur P, Force SD, Staley CA, Mansour KA, Miller JI, et al. Neoadjuvan chemoradiation versus chemotherapy for patients undergoing esophagectomy for esophageal cancer. Ann Thorac Surg. 2008;85:1217-23; discussion 1223-24.

27. Davies AR, Gossage JA, Zylstra J, Mattsson F, Lagergren J, Maisey N, et al. Tumor stage after neoadjuvant chemotherapy determines survival after surgery for adenocarcinoma of the esophagus and esophagogastric junction. J Clin Oncol. 2014;32:2983-90.

28. Rizk NP, Ishwaran H, Rice TW, Chen LQ, Schipper PH, Kesler KA, et al. Optimum lymphadenectomy for esophageal cancer. Ann Surg. 2010;251:46-50.

29. Koen Talsma A, Shapiro J, Looman CW, van Hagen P, Steyerberg EW, van der Gaast A, et al. Lymph node retrieval during esophagectomy with and without neoadjuvant chemoradiotherapy: prognostic and therapeutic impact on survival. Ann Surg. 2014;260:786-92; discussion 792-3.

30. Groth SS, Virnig BA, Whitson BA, DeFor TE, Li ZZ, Tuttle TM, et al Determination of the minimum number of lymph nodes to examine to maximize survival in patients with esophageal carcinoma: data from the Surveillance Epidemiology and End Results database. J Thorac Cardiovasc Surg. 2010;139:612-20.

31. Mariette C, Piessen G, Briez N, Triboulet JP. The number of metastatic lymph nodes and the ratio between metastatic and examined lymph nodes are independent prognostic factors in esophageal cancer regardless of neoadjuvant chemoradiation or lymphadenectomy extent. Ann Surg. 2008;247:365-71.

32. Gaur P, Sepesi B, Hofstetter WL, Correa AM, Bhutani MS, Vaporciyan AA, et al A clinical nomogram predicting pathologic lymph node involvement in esophageal cancer patients. Ann Surg. 2010;252:611-7.

33. Bolton WD, Hofstetter WL, Francis AM, Correa AM, Ajani JA, Bhutani MS et al. Impact of tumor length on long-term survival of pT1 esophageal adenocarcinoma. J Thorac Cardiovasc Surg. 2009;138:831-6.

34. van Westreenen HL, Westerterp M, Bossuyt PM, Pruim J, Sloof GW, van Lanschot JJ, et al. Systematic review of the staging performance of 18F-fluorodeoxyglucose positron emission tomography in esophageal cancer. J Clin Oncol. 2004;22:3805-12.

35. Heeren PA, van Westreenen HL, Geersing GJ, van Dullemen HM, Plukker JT. In fluence of tumor characteristics on the accuracy of endoscopic ultrasonography in staging cancer of the esophagus and esophagogastric junction. Endoscopy. 2004;36:966-71

Key Words: esophageal cancer, outcomes, surgery, chemotherapy, radiation

\section{Discussion}

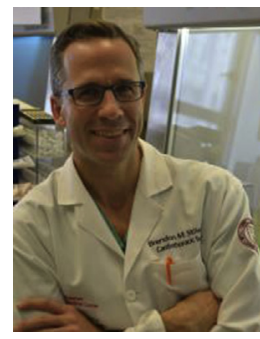

Dr Brendon M. Stiles (New York, $N Y$ ). Great job with the presentation and congratulations. I think even with all the appropriate caveats of big data research, this is a very important paper and we are happy that you presented it.

A couple of things really do suggest that maybe if you are going to do good surgery you don't need to do radiation, and so 
what do you think about this surgery? I know it is difficult in the National Cancer Database to tell what type of surgery they did, but you have a couple of surrogates that might say that the chemo only patients got better surgery, namely the lymph nodes.

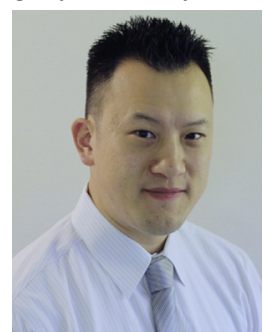

Dr Douglas Z. Liou (Stanford, Calif). Thank you. That is a good point. In this data set we aren't really able to delineate the type of esophagectomy that each group had. We recognize that the difference in the lymph node dissection could be a surrogate for the quality of the surgery performed, but I don't think we can tease that out with available data in the NCDB.

Dr Stiles. What else I think that you have to be careful about, there were only 440 patients in the chemo-alone group. Do you think that they were more likely to be operated at high volume centers; were you able to tell that from the data?

Dr Liou. It could be the case. There is regional data available in NCDB where you can look at percentage of surgery that was performed in different regions and we can extrapolate where those surgeries were done. We didn't look at that so far in this analysis, but we could.

Dr Stiles. And then I guess I was thinking about if I was a radiational oncologist, what would I say to the paper, and I would probably say, well, your complete pathological response rates were really only half of what it was for CROSS. Is that just a different regimen here or is this a real-world reflection? It is tough to give these patients full induction therapy.

Dr Liou. That is a good point. We speculate it is probably related to the specific induction regimen that was given. We don't have that data in the NCDB. But it is much lower than what we saw in, for instance, the CROSS study, which I think for adenocarcinoma was about $25 \%$. So, there was a difference there.

Dr Stiles. Great. Your conclusions were appropriately conservative, but I think this follows up nicely from work from Wash $U$ on the same database from a joint paper from John Spicer that we wrote with McGill and MD Anderson. So I am going to ask you, should we get rid of induction radiation as part of this regimen or should we at least use it selectively?

Dr Liou. I don't think we have enough robust data to say that with this paper. I think it would be important to answer that question. What we have shown here is that universally for patients with locally advanced disease, radiation may not be necessary in all patients but probably in some patients it will be important. We need more studies to look at specifically which patients those are going to be.

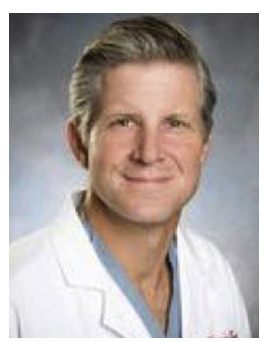

Dr S. Swanson (Boston, Mass). It was a really nice presentation. Do you have any data about-and you may have said this already-local recurrence in the two arms?

Dr Liou. We speculate most of the recurrence was distant recurrence based on prior studies, but we didn't present that data here because unfortunately recurrence is not captured in the NCDB.

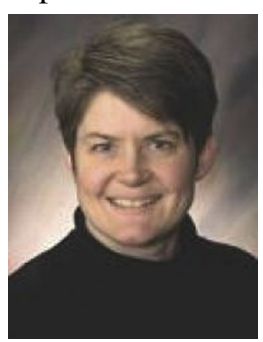

Dr Katie S. Nason (Pittsburgh, Pa). Dr Stiles raised a very important point about the community delivery of these regimens. The mortality is significantly higher in the community delivery of it, and it appears from your data that the complete response rates are lower. So, we are making decisions based on the trials that we are presented with, but the actual execution in the community might be far less than what we are able to do in these trials.

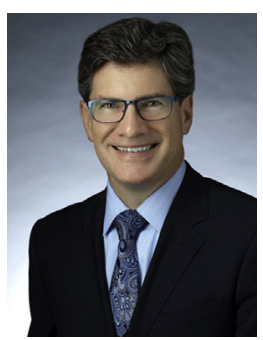

Dr Thomas J. Watson (Washington, $D C$ ). A very nice paper. The group that underwent chemoradiation had larger tumors, by and large, right?

Dr Liou. Correct.

Dr Watson. Yet they had a lower rate of positive margins.

Dr Liou. Correct.

Dr Watson. So maybe that could be a way to stratify radiation versus not. There could be some size criterion, perhaps.

Dr Liou. Right. We didn't specifically do subgroup analysis between larger tumors and smaller tumors. We could do that and go back and see if there is a difference. In our Cox model, it was not a significant factor in terms of tumor size, so we felt that was a pretty good marker. But we can go back and do that.

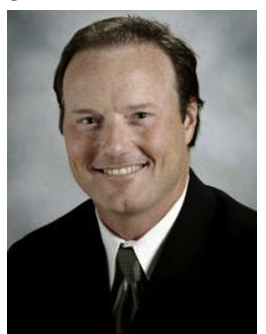

Dr Wayne L. Hofstetter (Houston, Tex). I have a question which is directed towards the NCDB database that you used. The data you presented was in the sixth edition AJCC. Is that the way they provided it to you?

Dr Liou. They include whatever the most recent version is. Our study went from 2006 to 2012, so it spans the fifth edition through the seventh edition, and so that affected the way we defined what locally advanced disease was.

Dr Hofstetter. When you were saying N1, that includes $\mathrm{N} 2$ and N3, so you captured all N positive, correct?

Dr Liou. Potentially. 


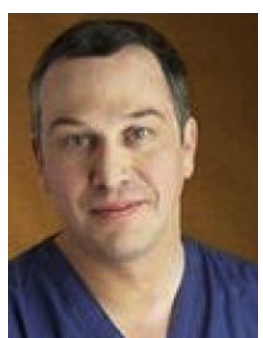

Dr A. Lebenthal (Boston, Mass). Is there any way of knowing how many Siewert $1 \mathrm{~s}$ versus $3 \mathrm{~s}$ were in the chemotherapy arm, because if what you are doing here is basically MAGIC for high gastric cancers, I don't know that there is anything new necessarily and I don't know that I would draw any conclusion for the esophagus from it.

Dr Liou. The way that the NCDB describe location is just based on the location in thirds, so this was distal third of the esophagus or the abdominal esophagus We don't have any data on what the Siewert classification was.

Dr Lebenthal. A lot of people that I get referred that are distal third are actually high stomach, so that's where the question is coming from.

Dr Liou. Right. Good point.

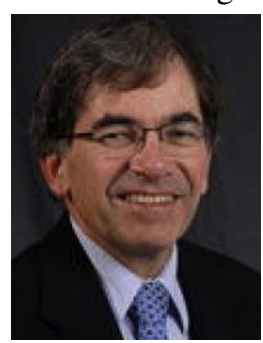

Dr Thomas M. Egan (Chapel Hill, $N C$ ). That was a nice presentation. Some of us are old enough to remember that very few of these patients survived long term before chemoradiation was introduced. Because your incidence of local eradication of tumor was higher with chemo rads, do you think that you have enough patients in the chemo only arm to make a conclusion that maybe the radiation isn't necessary, because a complete response is associated in large studies with better longterm survival.

Dr Liou. I am not sure that our data can really show that. Again, I think really what it is just saying is that we have two groups of patients who had two different types of treatment, but the radiation isn't necessarily useful in all patients with this stage of disease.

Dr Riyadh. The question is, despite the good local control with the chemoradiation group, the complete response and so on, there is no survival benefit. Is that due to like radiation complication, is there like early deaths due to complication from carcinoids?

Dr Liou. That is a good question. We can't really say based on a retrospective study like this. There are many factors that could be related to that. It could be the fact that, as was brought up, a difference in where the surgery was done, the quality of the surgery. Another thing we didn't mention and didn't show here was the incidence of adjuvant therapy, which was higher in the chemotherapy alone group compared to the chemoradiation group. These are all things that should be teased out in a more robust type of study design.

Readers who found these articles interesting may also like to read the following papers found in recent and future issues of our sister publications, Seminars in Thoracic and Cardiovascular Surgery and Operative Techniques in Thoracic and Cardiovascular Surgery!

Thoracic: Esophageal Cancer

STATE OF THE ART: Quality of Life after Open or Minimally Invasive Esophagectomy in Patients With Esophageal Cancer-A Systematic Review Emanuela Taioli. Semin Thoracic Surg 2017:377-390.

ORIGINAL SUBMISSION: Esophagectomy in Patients with Human Immunodeficiency Virus and Acquired Immune Deficiency Syndrome: A Viable Option. Michael Mwachiro. Semin Thoracic Surg 2017: In press. 